\title{
LOS ITINERARIOS DE CLÍO: ATISBOS A UN ENTRECRUCE DISCIPLINARIO
}

\section{THE ITINERARIES OF CLÍO: HINTS TO A CROSS-DISCIPLINARY}

\author{
José Solano Alpízar *
}

Fecha de recepción: 01/12/2017

Fecha de aceptación: 10/05/2018

Resumen: Este artículo muestra algunos de los desplazamientos -conceptos, temas, metodologías y estrategias analíticas- que ha experimentado la disciplina histórica a lo largo de la segunda mitad del siglo $\mathrm{XX}$ como producto de su entrecruce disciplinario con otros campos de las ciencias sociales y humanas, tales como la filosofía, la lingüística, la antropología y la sociología. Todo ello ocurre en un contexto de profundas transformaciones culturales, económicas, políticas, sociales y tecnológicas que servirán de bastidor para todo un conjunto de reflexiones teóricas, filosóficas, epistemológicas, éticas, metodológicas y estéticas, ${ }^{1}$ entre otras, que brindarán al historiador y a su disciplina nuevos elementos para adicionar a su ya nutrida caja de herramientas.

Palabras claves: historia; giro lingüístico; historiografía; interdisciplinariedad.

Abstract: This article seeks to show some of the displacements -concepts, themes, methodologies and analytical strategies- that historical discipline has experienced throughout the second half of the 20th century as a result of its disciplinary interrelations with other fields of social and human sciences, as philosophy, linguistics, anthropology and sociology. All this takes place in a context of profound cultural, economic, political, social and technological transformations that will serve as a background for a whole set of theoretical, philosophical, epistemological, ethical, methodological and aesthetic reflections, among others, that would give the historian and his discipline new elements to add to his already nourished toolbox.

Keywords: History; Linguistic Turn; Historiography; interdisciplinarity.

\footnotetext{
${ }^{*}$ Costarricense. Historiador y pedagogo. Profesor e investigador en el Centro de Investigación y Docencia en Educación (CIDE) y Centro de Estudios Generales (CEG), Universidad Nacional de Costa Rica (UNA). Correo electrónico: josesolanoalpizar@gmail.com

${ }_{1}$ Todo proceso de creación y recreación intelectual tiene una irrupción múltiple. No existe un momento fundante, una obra remite a otra obra, un momento a otro y un autor a otro. Existen esfuerzos intelectuales que tienen lugar en un fondo común, en este caso la cultura occidental, en donde teorías y enfoques desarrollados en los más variados campos del saber, pueden llevarse a cabo de manera paralela, complementaria o bien yuxtaponiéndose, dando lugar así a expresiones intelectuales que se contrarefieren unas a otras.
} 


\section{Las trompetas de la aurora: los heraldos de la "postmodernidad"}

“... para llegar al conocimiento, hay que ir tropezando con palabras que se han hecho duras y eternas como piedras...".

\section{F. Nietzsche}

Cada época produce interpretaciones sobre sí misma. Nuestra época no está exenta de ello, por esto los desplazamientos que ha experimentado la disciplina histórica se encuentran relacionados -al igual que en muchas otras disciplinas-al influjo y la afectación de una serie de cambios en el orden político internacional, giros económicos de gran impacto, transformaciones culturales, cambios científico-tecnológicos de grandes dimensiones, nuevas corrientes intelectuales y la emergencia de nuevas teorías y conceptos que acompañan nuevas formas de pensamiento, entre otras. Este conjunto de procesos, en su intersección y convergencia han dado lugar a eso que en los círculos intelectuales y académicos ha sido denominado como "postmodernidad", la cual designa, siguiendo a Lyotard, “... el estado de la cultura después de las transformaciones que han afectado a las reglas del juego de la ciencia, la literatura y de las artes a partir del siglo XIX" (2000, p. $9) .^{2}$

La "postmodernidad" constituye un momento de la modernidad en el que la humanidad ha experimentado transformaciones de gran envergadura en los más variados ámbitos de la sociedad y la cultura. ${ }^{3}$ Transformaciones que ya desde el siglo XIX se venían forjando con el surgimiento de nuevas maneras de pensar y nuevas discursividades que darían forma a movimientos sociales, políticos, culturales, económicos y científicos que en el siglo XX se expresarían de las más diversas maneras. Las principales críticas que el movimiento postmoderno realizará se dirigen no sólo a las certezas inmutables sobre las

\footnotetext{
${ }^{2}$ Una de las tesis centrales en la obra La condición postmoderna de Jean François Lyotard, es la desconfianza y el desencanto respecto de los grandes "metarelatos" de la historia, como por ejemplo la creencia de una sociedad sin clases como en el sistema filosófico de Marx o la Dialéctica del Espíritu Absoluto presente en la obra de Hegel. Al respecto véase: Lyotard (2000).

${ }^{3}$ Una caracterización amplia sobre la postmodernidad, sus causas y su desarrollo puede encontrarse en el trabajo de Best y Kellner. (1991).
} 
que se erigió el discurso de la modernidad, sino que además ponen en cuestión los grandes sistemas explicativos de la realidad como los de Hegel, Marx y Comte, ya que estos no sólo proveían una explicación racional y objetiva del orden social y económico imperante, sino que servían para modelar determinadas filosofías de la historia.

En virtud de ello, el siglo XIX se caracterizó por la puesta en cuestión de los enfoques predominantes en el campo de la historia; en este caso, ese enfoque historiográfico que privilegiaba la biografía de las grandes figuras del poder y rendía culto a los acontecimientos políticos, culto a los grandes personajes y a los hechos "trascendentales" que habían generado la disconformidad en algunos historiadores que consideraban necesario incorporar elementos de la cultura en el enfoque historiográfico vigente; tal es el caso, de la obra del historiador inglés Edward Gibbons Decadencia y caída del Imperio Romano (Burke, 2006, p. 16), la cual buscaba integrar a la historia política los aspectos socio-culturales.

Más adelante, estas mismas inquietudes estarían presentes en el territorio continental europeo pues, al lado de la tradición alemana, representada en la figura Leopoldo von $\mathrm{Ranke}^{4}$ quien posicionaba a la historia política y la rigurosa operación sobre las fuentes documentales en el pedestal del trabajo del historiador, mientras que la tradición francesa estaba representada por figuras como Jules Michelet o Fustel de Coulanges quienes creían que las investigaciones históricas debían considerar además la cultura, la religión, la familia y el Estado. De esta manera, y en un escenario de efervescencia intelectual, emergía el siglo XX arrastrando el lastre de la vieja historia decimonónica caracterizada por los grandes trabajos de historia política y "acontecimental", por un lado, mientras que por el otro, daba cabida a nuevas corrientes historiográficas que no sólo recogían las principales preocupaciones de la época, sino que planteaban su propia forma de hacer historia.

\footnotetext{
${ }^{4}$ De acuerdo con Burke, Leopold Von Ranke privilegiaba las fuentes contenidas en los archivos, lo que hacía parecer a los historiadores que trabajaban en historia social cultural como meros dilettanti. Al respecto véase: Burke (2006a).
} 
En Francia, serán Lucien Febrve y Marc Bloch ${ }^{5}$ las figuras más emblemáticas de ésta nueva generación de historiadores que transita del siglo XIX al siglo XX con una serie de ideas y nuevas formas de comprender y hacer la historia. Será gracias a su trabajo que se produce un proceso de reconfiguración histórica de la disciplina que habrá de influir notablemente sobre una pléyade posterior de historiadores ${ }^{6}$ que favorecieron con su quehacer el proceso de desplazamiento y entrecruce que experimentará la disciplina histórica durante la segunda mitad del siglo XX.

Como producto de esta forma de hacer historia, las primeras tres décadas del siglo XX verán florecer una inusual apertura de la disciplina hacia lo producido en otras áreas de saber, en un ambiente donde aún era fuerte el encierro disciplinario y la interdisciplinariedad una aspiración lejana. Este esfuerzo de apertura y desplazamiento inicial lo dejará entrever claramente Lucien Febvre en su ya clásica sentencia "Historiadores sed geógrafos. Sed Juristas también, y sociólogos y psicólogos" (Burke, 2006, p. 12). Esta colaboración con otras disciplinas, tales como la geografía, la sociología, la antropología, la lingüística, la psicología y la economía, anunciaba ya la posibilidad de futuros desplazamientos que al interior de la disciplina histórica redundaran en la determinación de nuevos objetos de estudio. De este modo se fueron decantando las preocupaciones fundamentales de esta nueva tendencia cuyo ascendiente sobre la historiografía contemporánea seria incuestionable ya que sus estudios vendrían a romper con la historia tradicional "hechológica" y "acontecimental" estableciendo las bases para una forma de hacer historia que elaboraba sus propios conceptos, "estructura", "coyuntura"

\footnotetext{
${ }^{5}$ Lucien Febvre y Marc Bloch son los fundadores de la Escuela de los Annales, corriente historiográfica francesa con una pródiga obra que ha escudriñado todos los ámbitos de la vida humana y no humana en la sociedad y la cultura, proponiendo nuevas miradas y con ellas la construcción de nuevos objetos, nuevos métodos y nuevos enfoques. Al respecto véanse las obras seminales: Febvre (1970) y Bloch (1982).

${ }^{6}$ La producción intelectual de la Escuela de los Annales ha sido agrupada de acuerdo a las generaciones de historiadores que han ido alimentando nuevas perspectivas historiográficas, y aunque no se trata de un grupo homogéneo y monolítico, se han establecido al menos tres generaciones de historiadores que inician con Lucien Febvre y Marc Bloch y continua con Fernand Braudel, George Duby, Jacques Le Goff, Phillipe Áries y Emanuel Le Roy Ladurie. Cercanos a estos -nos dice Burke- se encontrarían Ernest Labrousse, Pierre Vilar, Maurice Angulhon y Michelle Vovelle, quienes a pesar de su cercanía, tenían más compromiso con un enfoque marxista de la historia. Más allá del borde se puede situar a Michel Foucault. Luego aparecerán figuras como Robert Mandrou, Roger Chartier y Michel de Certeau.
} 
y diseñaba y ponía en ejecución sus propios métodos, como por ejemplo "la serie histórica" (Burke, 2006, p. 12).

La nueva corriente historiográfica francesa se nutriría no sólo de las preocupaciones intelectuales que tenían lugar en su propio campo de conocimiento, sino que también de las que acontecían en las disciplinas adyacentes, con lo cual estaba iniciándose un proceso paulatino de desplazamiento disciplinario que le permitiría a la disciplina, no sólo acceder a temas y problemas de los que se ocupaban la antropología, la economía, la psicología, la filosofía y la lingüística, sino también, adoptar y adaptar nuevos conceptos, metodologías y estrategias analíticas. Es así como junto a este significativo aporte de la escuela francesa de los Annales, también se debe mencionar la notable contribución de las corrientes históricofilosóficas alemana e inglesa, pues la confluencia de las reflexiones y planteamientos de estas tres corrientes con las que tenían lugar en otros campos de conocimiento, servirían de condición de posibilidad para el ulterior desarrollo de la disciplina histórica.

En este contexto, uno de los referentes fundamentales por su implicación posterior para el trabajo historiográfico es la obra de Friedrich Schliermacher, considerado el padre de la hermenéutica moderna, que si bien es cierto, se inscribe en el siglo XIX, no cabe duda de que influirá notablemente las preocupaciones intelectuales de autores como Martin Heidegger, Georg-Hans Gadamer y Reinhart Koselleck ya en el siglo XX. A este respecto, es oportuno destacar que aunque Schliermacher no era historiador, sino teólogo, su aporte al desarrollo historiográfico será fundamental, ya que para él la tarea de la hermenéutica era la de comprender el discurso igual o mejor que el autor, es por ello que en su obra hace depender el entendimiento de la interpretación del lenguaje y el pensamiento. No menos importante vendrá a ser el trabajo desarrollado por Wilhelm Dilthey ${ }^{7}$ quién no sólo hará una recuperación de la tarea que Schliermacher iniciará, sino que desarrollará un trabajo histórico-filosófico con el que ampliará el campo de aplicación de la hermenéutica a todas las ciencias humanas y sociales.

Finalmente, pero no por ello menos importante, es el aporte de la tradición inglesa de finales del siglo XIX y primeras décadas del siglo XX al desarrollo de la disciplina

\footnotetext{
${ }^{7} \mathrm{Al}$ respecto véase: Dilthey (1944).
} 
histórica. Éste aporte tendrá lugar, al igual que el de las dos tradiciones anteriores, en un período en el que la filosofía del orden y el progreso y la presunción lineal y evolutiva del desarrollo de la humanidad abrían la puerta a una disciplina historiográfica que adquiría su estatuto epistemológico de "cientificidad" gracias al impulso del positivismo dominante. Es en este contexto de ascenso de una disciplina científicamente posicionada -que se distancia del discurso literario- en la que se generan valiosos aportes al desarrollo de la disciplina gracias a la obra de Arnold Toynbee y de Robin Collingwood ${ }^{8}$ cuyas obras son de obligada referencia en este ejercicio de rastreo arqueológico.

De ésta manera y en el tránsito del siglo XIX al siglo XX es posible observar un desplazamiento en el campo historiográfico donde la vieja narración de los

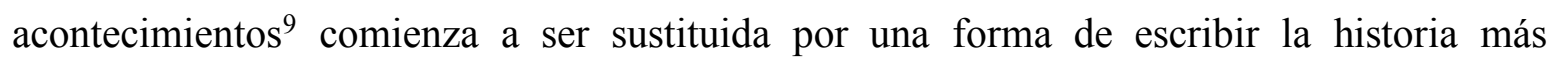
analítica en la que la formulación de problemas se convierte en la constante del quehacer investigativo y donde emergen numerosos trabajos en el campo de la "historia social", la "historia comparada", la "historia económica", la "historia de las mentalidades", la "microhistoria" y la "historia cultural".

\section{Historia y Filosofía: más allá de los límites de la razón ilustrada}

\section{“El acontecer de la historia es el acontecer del estar-en-el-mundo”.}

\section{Heidegger}

La filosofía es una de las disciplinas con la que la historia se ha intersectado desde tiempos de Tucídides, es por ello que este entrecruce disciplinario tiene que ser comprendido en el contexto del cuestionamiento sistemático de que ha sido objeto la

\footnotetext{
${ }^{8}$ Arnold Toynbee desarrolla una prolífica obra de investigación historiográfica (1934-1961) que se encuentra compilada en doce tomos y se conoce como A Study of History, mientras Robin Collingwood produce numerosos trabajos dentro de los que destaca The Idea of History.

${ }^{9}$ De acuerdo con Burke, en el ámbito de las ciencias sociales existía un particular punto de vista sobre la forma en que venían haciendo las cosas los historiadores, es por ello que François Simiand -discípulo de Durkheim- planteaba que se debían derribar "los ídolos de la tribu de los historiadores": el "ídolo político" que se asentaba en la historia política, el "ídolo individual" que se centraba en las grandes figuras del poder y el "ídolo cronológico", que se preocupaba por una búsqueda incesante por los orígenes (Burke, 2006, p. 18).
} 
filosofía moderna y las filosofías de la historia a partir del siglo XIX. La propia concepción dominante de historia a la que se le comenzó a hacer cuestionamientos en este siglo se encontraba fuertemente anudada a esas grandes concepciones filosóficas de la historia las cuales llegaron a permear todo el pensamiento de la modernidad. Es a finales del siglo XVIII, pero mayormente en el siglo XIX cuando aparece una nueva temporalización de la historia, donde lo cronológico adquiere un sentido histórico propio, pues como bien señala Koselleck es a partir de este momento que el concepto de historia tal y como lo conocemos hoy día comienza a gestarse, pues anteriormente a esto lo que existía era una historia que organizaba Dios con la humanidad, ya que no existía ninguna historia cuyo objeto hubiese sido la humanidad o una historia que se pudiese pensar como sujeto de sí misma (1993, p. 253).

Tal y como lo destaca Koselleck, antes de la existencia de esta concepción unitaria de historia no existía una historia integradora, universal y homogénea, lo que existía eran muchas "clases de historias" que eran utilizadas para la enseñanza en diferentes campos. No será sino hasta este momento que emerja una "historia absoluta" que reúna la suma de todas las historias individuales y con ella una concepción histórica como la de Hegel quién llegará a caracterizar la historia universal como “... la exposición del proceso divino y absoluto del espíritu, en sus formas supremas; la exposición de la serie de fases a través de las cuales el espíritu alcanza la verdad, la conciencia de sí mismo (Hegel, 1999, p. 76).

De acuerdo con la lógica hegeliana, el progreso resumía la relación entre pasado y presente, en la que la historia era interpretada como el proceso dinámico que unía el pasado con el presente a través de una serie de etapas dirigidas hacia la plena realización de la humanidad. En ésta perspectiva idealista ${ }^{10}$ la historia pasaba a ser concebida como la expresión del espíritu absoluto que se desplegaba como la sucesión de un conjunto de

\footnotetext{
${ }^{10} \mathrm{La}$ otra gran filosofía que va a dar sustento al discurso de la modernidad es la que surge con la obra de Marx, en la cual se erige al hombre como protagonista de la historia. Esta visión, denominada materialismo histórico, estará afirmada en dos premisas fundamentales: el carácter material de las relaciones que el hombre establece con otros hombres y con la naturaleza y la existencia de unas relaciones de producción e intercambio de bienes materiales con la que los hombres reproducen sus condiciones materiales de existencia.
} 
estadios en un horizonte temporal cruzado por la idea de un progreso lineal y evolutivo de la humanidad.

\section{Nietzsche y Heidegger: los filósofos de la destrucción}

En un escenario en el que dominaban las grandes filosofías de la historia emerge la obra de Friedrich Nietzsche para combatir las tesis idealistas y poner en cuestión -a través de su analítica genealógica- los fundamentos del pensamiento moderno y de la propia racionalidad occidental. ${ }^{11} \mathrm{Su}$ recelo frente a la metafísica lo llevará a cuestionar al historicismo ${ }^{12}$ y con éste a la visión lineal y evolucionista de la historia que la sustentaba, pues para Nietzsche el historicismo había venido promoviendo una perpetuación del pasado, razón por la que había que hacer una reinterpretación del pasado donde la subjetividad jugaba un papel determinante. De ésta forma la genealogía nietzscheana venía a oponer la subjetividad y la interpretación a una objetividad que se había develado ficticia. Para Nietzsche un fenómeno, un objeto un acontecimiento carecían de esencia más allá de la historia, tras de ellas se escondían una variedad de sentidos que solo podían ser comprendidos mediante un movimiento de la propia subjetividad (Moro Abadía, 2006, p. $55)$.

Esta apelación a la subjetividad, unida a la crítica de la ontología tradicional y la linealidad de la historia, se constituyó en herramientas útiles para el cuestionamiento posterior de uno de los presupuestos metódicos del historicismo que tanto Ranke como sus discípulos habían proclamado y, según el cual, todo historiador debía limitarse a conocer los datos y expresar lo que estos le daban a conocer, sin dar cabida a juicios subjetivos o permitirse los arrebatos de la imaginación.

En virtud de ello, no es casual que la obra de Nietzsche se constituyera en referente del cual abrevarían muchos de los intelectuales del siglo XX y sirviera de insumo para el

\footnotetext{
11 La obra de Nietzsche es pletórica en observaciones y cuestionamientos a los fundamentos de la modernidad. La escritura irónica del "filósofo de la destrucción" pone en suspenso la creencia de una historia encarnada en la idea de un espíritu universal.

${ }^{12}$ Por historicismo podemos entender la corriente filosófica, que a partir de algunas de las tesis de Benedetto Croce -italiano- y Leopoldo Van Ranke -alemán- conciben la realidad como la resultante de un devenir histórico. El ser es pensado como un devenir, un proceso temporal que no puede ser captado por la razón.
} 
desarrollo de nuevas propuestas teóricas y reflexiones filosóficas y epistemológicas tales como la hermenéutica de Georg-Hans Gadamer, la genealogía de Michel Foucault, la filosofía deconstructiva de Jacques Derrida, la filosofía de la diferencia de Gilles Deleuze y el pensamiento débil de Gianni Váttimo. Ahora bien, otra de las figuras destacadas en este periodo, cuya obra será referente, es la de Martin Heidegger en quien al igual que en Nietzsche se encuentra un esfuerzo decidido por poner en cuestionamiento los fundamentos de la metafísica occidental. De acuerdo con la concepción filosófica de Heidegger, la metafísica iniciada con la filosofía antigua y desarrollada después por la filosofía moderna "olvidó al ser"; es decir, olvidó la diferencia ontológica entre "ser" y "ente" y, con ello, la filosofía moderna devino en metafísica.

De acuerdo con Heidegger, la historia humana inicia su devenir con la metafísica ya que para él la historia occidental es el desenvolvimiento mismo de la metafísica, primero como la idea del bien según la filosofía de la antigüedad clásica, luego como la idea del Dios supremo como en la filosofía escolástica y finalmente como la supremacía del sujeto expresada en la filosofía de la modernidad. Esta primacía del sujeto en el discurso de la modernidad es consecuencia directa del giro antropocéntrico dado por el humanismo y retomado por el pensamiento de la Ilustración que posicionaba al sujeto como el dador de sentido a priori a un mundo construido y pensado por él y para él. En palabras de Gadamer, en la obra Ser y tiempo, Heidegger da un nuevo enfoque a la historicidad de la existencia humana al liberar el problema de la historia de los presupuestos ontológicos que lo constituían. Según esto, Heidegger muestra en sus reflexiones que ser no significaba, necesariamente, objetividad, introduciendo en el pensar la indagación acerca de la diferencia genérica existente entre lo óntico y lo histórico (1986, p. 39).

A este respecto, Heidegger advierte:

La historicidad, es decir, la temporalidad, significa ser en un sentido más originario que el estar ahí dado y que la ciencia natural trata de conocer. Hay una razón histórica porque la existencia humana es temporal e histórica. Hay una historia mundial porque esa existencia temporal del hombre "tiene un mundo". Hay cronología porque la existencia histórica del hombre es tiempo (Heidegger, citado por Gadamer, 1986, p. 39). 
De ésta manera el pensamiento filosófico de Heidegger se constituye junto con el de Nietzsche en una nueva vía de interpretación de la historicidad de la existencia humana y, con ello, en una grieta en el pensamiento de la modernidad que servirá de insumo a las interpretaciones anti-esencialistas que darán contenido a los desplazamientos que tendrán lugar al interior de la filosofía y la historiografía contemporánea y de las ciencias sociales y humanas en general.

\section{El despertar de la imaginación: subjetividad y narratividad en la "Nueva Historia"}

En el mismo periodo en que aparece la obra de Heidegger, irrumpe en el escenario intelectual la obra La idea de la historia ${ }^{13}$ del historiador y filósofo de la historia inglés Robin Collingwood quién lanza al escenario intelectual de la primera mitad del siglo XX el tema de la narrativa histórica y el uso de la imaginación en el trabajo del historiador. Esta mirada del filósofo inglés en las primeras décadas de este siglo servirá para alimentar de manera directa o indirecta una concepción de la historia que comienza a movilizarse desde una concepción de la historia como expresión de una realidad pasada que el historiador debe relatar de manera objetiva y apegada a lo que dictan las fuentes, a una concepción en la que la subjetividad del historiador juega un papel determinante, pues es él quién le dará sentido a la narración histórica a partir de un uso riguroso de las fuentes utilizadas.

Se trata de un reconocimiento del papel de la imaginación del historiador como un mecanismo para acceder al conocimiento de la historia y darle sentido a aquellos vacíos de los que no se tiene mayor información a la mano, y se constituirán -con el correr del tiempo-, en elementos fundamentales para la interpretación historiográfica y para el retorno a la narración que experimentará la disciplina historiográfica en las últimas tres décadas del siglo XX. ${ }^{14}$ A su vez constituirá una apertura a los giros que han tenido lugar en otros

\footnotetext{
13 Collingwood (1965).

14 Como bien lo destaca María Lúcia Pallares-Burke, obras como las de Ginzburg (1986) -publicado en 1976-; Davis (1982) y Schama (1999), acusadas de parecer más novelas históricas que verdaderos trabajos historiográficos marcan el camino hacia la "Nueva Historia". Al respecto véase: Garcia Pallares-Burke (2005) y Aurell (2005).
} 
campos de conocimiento y han servido a la historiografía contemporánea para decantar nuevos itinerarios y no pocas renuncias a un pasado signado por la fe ciega en la objetividad de la tarea historiográfica, la creencia en la verdad y la universalidad de su propio discurso. De igual manera que significará la apertura a la idea de la historia como texto que tendrá lugar en el marco del "giro lingüístico" de los años setenta del siglo XX, donde emerge la idea del carácter contingente del lenguaje y de las propias prácticas discursivas, la cual vendrá a darle a la disciplina histórica nuevas direccionalidades, mismas que encontraran en la obra de autores contemporáneos nuevos elementos para su desarrollo.

\section{El giro cultural y las nuevas interpretaciones filosóficas}

La influencia de Nietzsche y de Heidegger marca las reflexiones y propuestas de autores como Georg Hans Gadamer, Michel Foucault, Jacques Derrida, Gilles Deleuze y Hayden White a lo largo de la segunda mitad del siglo XX quienes desarrollan una obra prolija que impacta de manera directa e indirecta a la historiográfica de su época, ya que teorías que campean en el marco historiográfico contemporáneo son puestas en cuestión por los nuevos enfoques filosóficos y las nuevas corrientes del pensamiento histórico que emergen en las últimas décadas de este siglo. Es así como, frente a la fuerza irreductible del positivismo y del marxismo que por largo tiempo se esforzaron por hacer hablar a los hechos y arrancarles la verdad que atesoraban a partir de un uso riguroso del método y un trabajo minucioso con las fuentes emerge una nueva forma de acercarse a la historia, no ya desde el principio de universalidad, ni desde la asepsia interpretativa del historiador, sino desde una comprensión de la cultura, la historia y la sociedad como un texto al que es posible leer y deconstruir.

En este contexto, el influjo de las teorías estructuralistas -Levi Strauss, Lacan, Althusser-, posestructuralista -Foucault, Derrida-, hermenéutica -Gadamer- y la filosofía de la diferencia -Deleuze-, en el intersticio con la pragmática del lenguaje anglosajona -Wittgenstein, Searle, Austin, Rorty- y las nuevas filosofías de la historia -Hayden, LaCapra, Ricoeur- servirán de sustrato intelectual para que las diferentes ciencias sociales 
y humanas realicen nuevas elaboraciones teóricas y epistemológicas a partir de nuevos problemas, objetos, conceptos, temas y metodologías. El "giro cultural" que presupone grandes aportes y mutaciones desde la filosofía, la lingüística y la antropología cultural, redefine el concepto de cultura y con ello la forma de aproximarse a las prácticas culturales y la historicidad que le es consustancial, de ahí que se pase a conceptuar la cultura como un corpus de códigos tal y como lo hace Roland Barthes, como un conjunto de resoluciones imaginarias de contradicciones reales en el caso de Claude Levi-Strauss o bien como un texto tal y como lo plantea Clifford Geertz.

Las filosofías subyacentes a este "giro cultural" irrumpen en la escena historiográfica contemporánea y rompen con la forma de acercarse a la historia e interpretarla. La obra hermenéutica de Georg-Hans Gadamer por ejemplo plantea la idea de que comprender es de por sí ya una interpretación, tal y como lo había enunciado Schliermacher tiempo atrás (Gadamer, 1986, p. 26). Ello nos lleva a la idea de que toda lectura del texto en la investigación histórica presupone, no sólo el ejercicio de interpretación, sino también la incorporación de nuevos sentidos. El texto no está autocontenido en sí mismo, no tiene un sentido último que hay que descubrir.

En este sentido y tal como lo destaca Gagliano, la centralidad del lenguaje en la nueva escena intelectual de la segunda mitad del siglo XX presupone al mismo tiempo que éste pierda la centralidad que tenía como autor de las narrativas de sentido único que configuraron los ideales y esperanzas de la modernidad, pues este descentramiento le quito al discurso histórico el peso normativo de relato sustentado en la salvación, el progreso o la emancipación, construido como el espacio privilegiado donde la experiencia del pasado resuma pedagogía de vida en el presente y preconfigura las líneas de acción del porvenir (2006, p. 251).

Una línea que se interseca al interior de este multireferencial "giro cultural" es el trabajo desarrollado por Michel Foucault a partir de la década de los años sesenta del siglo pasado y que como ha señalado Paul Veyne ${ }^{15}$ vino a revolucionar la historia no sólo por su

${ }^{15}$ El trabajo de Paul Veyne permitió la introducción de la obra foucaultiana en el espectro intelectual de la época. Al respecto veáse: Veyne (1984).

Revista Perspectivas: Estudios Sociales y Educación Cívica - No 16 ISSN-L: 2215-4728 • enero-junio 2018 • pp. 1-24 http://dx.doi.org/10.15359/rp.16.1 
propuesta epistemológica, sino también por el aporte de nuevos métodos, estrategias analíticas y conceptos que servirían para repensar el quehacer historiográfico y abrir nuevas perspectivas para la investigación interdisciplinar. De clara filiación nietzscheana, Foucault ${ }^{16}$ representa un salto en el forma de concebir el trabajo historiográfico, pues echando mano de la etnología y del psicoanálisis elabora una propuesta teórica que se deslinda de la clásica noción de periodicidad para incorporar la noción de discontinuidad que le permite reconstruir diferentes epistemes desde una lógica de coexistencia y heterogeneidad que no se deja sujetar por la idea de un tiempo continuo, homogéneo y lineal que es posible reconocer a partir de la personificación del pasado. Su obra en general, pero sus estrategias analíticas -genealogía, arqueología, biopolítica- en particular, vendrán a constituirse en instrumentos fundamentales para el trabajo de los historiadores interesados en desentrañar los laberintos del discurso y las prácticas discursivas.

Otros dos autores posestructuralista franceses cuyas obras vienen a impactar el trabajo historiográfico de manera directa son Jacques Derrida ${ }^{17}$ y Gilles Deleuze. El primero con su aporte a la filosofía desde la estrategia analítica deconstructiva y su noción de texto como ámbito de producción cultural de significados en el que se parte de la premisa de que el autor no tiene ninguna relación con los textos y más bien estos deben ser concebidos no como un corpus finito de escritura, sino como una red diferencial, es decir, como un "tejido de huellas" que remite indefinidamente a algo distinto que ellas mismas (Granja, 1996, p. 20). Esta concepción del texto abrió las posibilidades analíticas en historia en un momento en el que se comenzaba a dar un retorno a la narratividad y en el que "... el relato histórico postmoderno con su gramática recursiva no aspiraba ya a contar hechos nuevos, sino a producir una narrativa que organiza figurativamente el cambio radical presente en el régimen de significación epocal en los inicios del siglo veintiuno" (Gagliano, 2006, p. 253).

\footnotetext{
${ }^{16}$ Para una profundización de estas ideas véase: Foucault (1996a) y (1996b).

${ }^{17}$ Dos de las obras más representativas de Derrida y de las cuales es posible sustraer algunas de sus principales ideas son: Márgenes de la filosofía así como La escritura y la diferencia. Al respecto véase: Derrida (1988) y (1989).
} 
De acuerdo con Best y Kellner, afirmado en un trabajo que encuentra sus ecos en la obra de Nietzsche, Deleuze postula junto a Félix Guattari una propuesta teórica que busca crear nuevas formas de pensar, de subjetividad y de política, ya que su obra el Antiedipo constituye una crítica provocadora de los discursos e instituciones de la modernidad que reprimen el deseo y la proliferación de subjetividades fascistas que rondan incluso los movimientos revolucionarios $(1991, \text { p. } 76)^{18}$. De acuerdo con estos autores, su estilo profuso de escritura y el empleo de numerosos neologismos permitió la creación de conceptos como los de "rizoma", "cuerpo sin órganos" y "esquizoanálisis" que se constituyeron en parte del andamiaje conceptual mediante el cual se articulaba el análisis deleziano y desde el cual se analizaba el desarrollo del capitalismo no desde la lectura marxista de los modos de producción, sino desde lo que denomina como "máquinas sociales" y "flujos sociales".

Finalmente debemos mencionar el trabajo emblemático del filósofo de la historia Hayden White, cuya propuesta epistemológica no solo recupera los elementos fundamentales de la corriente "postmoderna", sino que introduce nuevas formas para abordar el trabajo en historia a partir de un rechazo abierto a los presupuestos ontológicos y epistemológicos sobre los que se había venido inscribiendo el trabajo historiográfico en la modernidad. Su obra se inscribe en el movimiento iniciado ya desde el siglo XIX y que en la década de los años setenta del siglo XX culmina con la anulación y la desestimación de la idea de una historia objetiva y transparente que acude a la verdad de los hechos a partir de un trabajo riguroso con las fuentes documentales. En este nuevo suelo epistémico, se parte del presupuesto de que el historiador impone su propia visión al seleccionar una determinada teoría y al seleccionar y privilegiar unos determinados documentos por sobre otros.

Como el propio White (2003) lo señala:

\footnotetext{
${ }^{18}$ Best y Kellner realizan un detallado análisis del trabajo de Deleuze y Guattari en su obra sobre la teoría postmoderna. Al respecto véase: Best y Kellner (1991).
} 
La escritura histórica es un medio de producción de significado. Es una ilusión pensar que los historiadores solo desean contar la verdad acerca del pasado. Ellos también quieren, lo sepan o no, pero en cualquier caso deberían querer, insistiría, dotar al pasado de significado (pp. 52-53).

Es así como la narratividad se constituye en una forma de representar el pasado que produce significados y un efecto de realidad. El discurso narrativo marginado y soslayado en la historiografía a lo largo del siglo XX, debido a su supuesta incompatibilidad con la seriedad y rigurosidad del lenguaje científico, adquiere a partir de ese momento un lugar medular en el que se le atribuirá un carácter de agente creativo en el proceso de representación de los hechos del pasado.

\section{Historia y lenguaje}

"Sin acciones lingüísticas no son posibles los acontecimientos históricos; las experiencias que se adquieren desde ellos no se podrían interpretar sin lenguaje”.

Durante mucho tiempo, el tipo de historia que se escribía no consideraba límites tan claros entre imaginación y realidad. De hecho, señala Antonia Viú, para un historiador como Heródoto la objetividad y la verdad no eran una exigencia para el cabal cumplimiento de su oficio, ya que en este periodo la distancia entre la narración ficcional y la narración histórica no estaba tan claramente delimitada, será posteriormente que se irá haciendo un distanciamiento entre la realidad y la ficción, a partir del principio de verdad que será el elemento articulador de la nueva interpretación historiográfica. Esta preocupación por la verdad, -destaca Viú- que en la época griega es posible apreciar en Tucídides, ya en la última parte del siglo XVI y sobre todo en el siglo XIX, encontrará su máxima expresión con el proceso de cientifización del quehacer historiográfico, cuyo método riguroso debía conducir a una investigación documental que garantizara la verdad de los hechos analizados (2007, p. 33). 
Con las filosofías de la historia que emergen en este siglo -como Hegel, Marx-, la concepción de historia que va a predominar estará asociada a los principios de verdad y de objetividad propios del positivismo en boga. El trabajo del historiador deberá garantizar por un lado que, el uso que se hace de las fuentes es objetivo y por lo tanto apela a los hechos tal y como acontecieron y, por el otro, que se apela a las fuentes documentales de una manera rigurosa sin dar pie a interpretaciones subjetivas donde se involucre la imaginación de quién reconstruye el hecho histórico. Visto en esta perspectiva, el trabajo del historiador refiere a un ejercicio de interpretación donde la verdad está dada por el acceso y el uso de las fuentes documentales, que se constituyen en los depositarios de una verdad que el historiador cuenta de manera real y efectiva, apegándose a lo que los hechos determinan y las fuentes establecen.

Esta forma de concebir el trabajo del historiador comenzará a ser cuestionada, tal y como ha sido señalado, al aparecer en escena la imaginación como uno de elementos fundamentales en el ejercicio de investigación histórica. La separación impuesta entre historia y ficción y entre obra histórica y novela que en el siglo XIX alcanza su mayor expresión, comenzará a agrietarse y dar pasó a una interpretación según la cual la objetividad del historiador es cuestionada debido a que su participación en la determinación del tema a investigar encubre su propia subjetividad, pues éste elige su tema a partir de una serie de creencias, valores y conocimientos que influyen de manera directa o indirecta en el resultado de la investigación. Este reconocimiento de la subjetividad del historiador frente al objetivismo dominante, constituirá uno de los principales movimientos que experimente la disciplina histórica en la primera mitad del XX, la que unida a la consideración de la historia como un texto, servirá para dar una nueva direccionalidad a la historia como campo de conocimiento. ${ }^{19}$

\footnotetext{
${ }^{19}$ Quizá uno de los antecedentes sobre el papel del lenguaje, de cara al "giro lingüístico" que tendrá lugar en la segunda mitad del siglo XX, sea la obra de Nietzsche como ha sido señalado. Su aguda visión de las cosas aunada a sus preocupaciones filológicas y filosóficas le permite a este, realizar algunas digresiones en torno al origen social del lenguaje, dado que para él, este se encuentra en el mundo de lo social.
} 
El 1lamado "giro lingüístico"20 que tendrá lugar en la segunda mitad del siglo XX servirá para potenciar los desplazamientos al interior de la disciplina histórica y permitirá repensar la historia a partir del papel asignado al lenguaje y a las prácticas discursivas como constructoras de la realidad socio-histórica. El surgimiento de nuevos enfoques y teorías en la disciplina pasará por el cambio de una visión de la historia presentada como una verdad objetiva y universalmente aceptada, al de una interpretación historiográfica en la que se realiza un uso específico del lenguaje, es decir, donde la "...significación de un hecho no está dada porque el historiador permite que aquel encuentre su voz, sino que un relato probable pueda inscribir una interpretación verosímil en el concierto de otras interpretaciones posibles" (Gagliano, 2006, p. 251).

En esta nueva perspectiva, la historia deja de ser la propietaria autorizada de una verdad atesorada en los documentos y los rigores de la metodología para pasar a constituirse en "una red lingüística arrojada hacia atrás" (Steiner, citado por Aurell, 2005, p. 122) o en "la recopilación de la obra del espíritu humano, escrita en lenguajes del pasado, cuyo texto hemos de entender" (Gadamer, citado por Aurell, 2005, p. 122). En este giro lingüístico se dirime algo más que un juego de palabras, ya que se dota de materialidad a la retórica y se atribuye un contenido a la forma. Sí las palabras, señala Aurell, son las que cuentan en la narración histórica, el modo de organizar esos signos pasará a ocupar un lugar privilegiado en la construcción de la obra histórica (2005, p. 123).

De esta manera, el discurso narrativo soslayado anteriormente por ser considerado un discurso poco académico, encontrará en este nuevo periodo histórico las condiciones apropiadas para su desarrollo, las condiciones de posibilidad estarán dadas en un contexto en el que irrumpe con denodada vitalidad el denominado movimiento "postmoderno" y hace su emergencia una visión de la realidad, la sociedad y la cultura que sospecha de toda certidumbre y pone en suspenso toda posibilidad de alcanzar el conocimiento de forma objetiva y veraz.

\footnotetext{
${ }^{20}$ El llamado "giro lingüístico" es una expresión acuñada por Gustav Bergman en 1964, sin embargo va a ser Richard Rorty quién posicione la expresión en un contexto más amplio a través de una colección de ensayos editados por él. Al respecto véase: Rorty (1967).
} 
No es casual el surgimiento de nuevas teorías y enfoques para explicar la realidad, pues el agotamiento de los antiguos paradigmas explicativos de la realidad social y la cultura -marxismo, estructuralismo, positivismo- que habían campeado en el pensamiento occidental durante la primera, y gran parte de la segunda mitad del siglo XX darán paso a una interpretación socio-cultural más abierta y relacional en la que el lenguaje se constituye en el punto de referencia y nudo de explicación del quehacer humano. La nueva narración histórica emerge después de haber estado sepultada bajo el lastre del historicismo cientificista que la había confinado a un lugar marginal dentro del trabajo historiográfico, ahora los métodos y los criterios de demarcación científica pasarán a tener un peso relativo en la construcción del relato histórico y la distancia entre la historia y la ficción, asentada sobre la objetividad y fundada en criterios de referencialidad y veracidad se reducirá hasta hacerse borrosa, pues se cae en cuenta de que estos no eran más que estrategias retóricas del mismo tipo que las empleadas por la ficción (Viú, 2007, p. 43).

Obras como Bandidos de E. J. Hobsbawm (1969), Un domingo en Bouvines: 24 de julio de 1214 de George Duby (1973), El queso y los gusanos: El cosmos según un molinero del siglo XVI de Carlo Ginzburg (1976), Le Retour de Martin Guerre de Natalie Zemon Davis (1982), La gran matanza de gatos y otros episodios de la historia de la cultura francesa de Robert Dartnon (1984) y Rembrandt's Eyes de Simon Schama (1999) por mencionar algunos, marcaran un paulatino, pero a la vez seguro desplazamiento de la historiografía en dirección de la denominada "nueva historia" 21 . En este contexto, el "giro lingüístico" contribuirá significativamente a revisar las formas de escribir la historia. El oficio del historiador no será ya más el de un erudito frente a documentos mudos a los que hace hablar y les arranca la verdad.

Desde la irrupción de la imaginación que realizara Collingwood en la década de los años cuarenta del siglo pasado, la subjetividad del intérprete sobre las fuentes a las que acude para describir un acontecimiento no es ni neutra ni objetiva, por el contrario, el

\footnotetext{
${ }^{21}$ Ya desde el trabajo pionero de Lucien Febvre y Marc Block se habían trazado algunas de las líneas que más tarde recorrerían "la historia de las mentalidades" y posteriormente la "historia cultural". Al respecto véase: Burke (2003), Garcia Pallares-Burke (2005) y Aurell (2006).
} 
discurso histórico no se limita a transmitir hechos, sino también a organizarlos e interpretarlos. Nuevos enfoques, ya sea desde la "historia de los conceptos" -Koselleck-,22 "la microhistoria" -Carlo Ginzburg-, la "historia cultural" -Natalie Z. Davies- o la "nueva historia" -Hayden White- ${ }^{23}$ vendrán a alimentar el enfoque historiográfico contemporáneo de entrada al siglo XXI. Si bien es cierto, desde la obra de Marc Block y Lucien Febvre -fundadores de la Escuela francesa de los Annales- se habían demarcado muchos de los territorios por donde podría discurrir la historiografía de nuestro tiempo es en el entrecruce disciplinario de la segunda mitad del siglo XX que la historia va a desplazarse continuamente para albergar nuevos problemas, temáticas y metodologías; desplazamientos que no podrían ser comprendidos al margen de los procesos socio-históricos que han tenido lugar en el marco más amplio de eso que denominamos con cierta reticencia como “postmodernidad".

Los recorridos de la nueva historia, que acudirá a temas, ámbitos y actores otrora soslayados o bien poco estudiados por la historiografía dominante muestran uno de los principales desplazamientos de la disciplina histórica en busca de su propia identidad. Por ello no es fortuito que, a lo largo de la segunda mitad del siglo XX, se haya venido abriendo -como bien los señala Stone- a investigaciones relacionadas con:

[...] la naturaleza del poder, la autoridad y el liderazgo carismático; la relación de las instituciones políticas en las que subyacen pautas sociales y sistemas de valores; las actitudes de la juventud, la vejez, la enfermedad y la muerte; el sexo, el matrimonio y el concubinato; el nacimiento, la anticoncepción y el aborto; el trabajo, el ocio y el consumo conspicuo; la relación de la religión, la ciencia y la magia como modelo explicativo de la realidad; la fuerza y dirección de las emociones, del amor, el miedo, la lujuria y el odio; el impacto de la alfabetización y la educación en la vida de las personas y formas de ver el mundo; la importancia relativa atribuida a la agrupación de diferentes sistemas sociales,

\footnotetext{
${ }^{22}$ Sobre la historia de los conceptos véase: Koselleck (1993), (2001) y (2004).

${ }^{23}$ Uno de los aportes más relevantes para la historiografía contemporánea es la de Hayden White desde la filosofía de la historia, su obra marca un punto de ruptura epistemológica al proponer la narrativa como forma de representación del pasado que produce significado y un efecto de realidad. Al respecto véase: White (1992).
} 
como la familia, familiares, comunidad, nación, clase y raza; la fuerza y el significado del ritual, el símbolo y la costumbre como forma de obligar a una comunidad en conjunto; los enfoques filosóficos y morales a la delincuencia y el castigo; los patrones de deferencia y los estallidos de igualitarismo, los conflictos estructurales entre los grupos de status o clases, y el medio, las posibilidades y limitaciones de movilidad social; el significado de la naturaleza de la protesta popular y las esperanzas milenaristas; el cambiante equilibrio ecológico entre el hombre y la naturaleza; las causas y los efectos de la enfermedad ... (Stone, 1979, p. 15).

La nueva historia forjada inicialmente por los seguidores de la Escuela de los Annales y que dará luego contenido a una tendencia historiográfica a la que se denominará en la década de los años ochenta del siglo pasado como "nueva historia cultural" son tributarias de todo este conjunto de vertientes de pensamiento que les han permitido alcanzar la corporeidad teórica, metodológica y epistemológica que hoy se les reconoce. En virtud de ello, no podría soslayarse la idea que desde la fijación historicista del siglo XIX a hoy, la disciplina histórica ha experimentado numerosos procesos de desplazamiento, tanto como producto del entrecruce con otros campos de saber, como por la propia dinámica interna que la ha llevado a poner en cuestión los fundamentos teóricos, metodológicos y epistemológicos sobre los que se había erigido la construcción historiográfica en la modernidad.

\section{Consideraciones finales}

Tal y como se ha querido mostrar a lo largo del presente artículo, la disciplina histórica -al igual que otros campos disciplinarios- ha venido experimentado un serie de desplazamientos que han llenado de nuevos sentidos su quehacer. Dichos desplazamientos han tenido lugar, no sólo en el campo teórico o metodológico, sino que han sido perceptibles también a nivel epistemológico. El tránsito de una visión historicista

${ }^{24}$ Durante la década de 1980, Lynn Hunt coordinó la publicación de una obra en la que se recogían las principales tendencias historiográficas de la época. Allí se apela directamente a la "nueva historia cultural". Al respecto véase: Hunt (1989). 
decimonónica afincada en la cientificidad de su quehacer y respaldada por un purismo metodológico y un respeto absoluto a lo "que dicen los hechos" hacia una historia abierta a lo producido en otros campos disciplinarios que acoge métodos, conceptos y problemas que le eran ajenos a la perspectiva historiográfica anterior, marcan un primer gran giro de la historiografía en la época contemporánea. Los ecos procedentes del pensamiento antimetafísico de Nietzsche, en un primer momento, y de Heidegger en un segundo momento, se entrecruzarán con los planteamientos de historiadores y filósofos de la historia -Dilthey, Collingwood, Febvre, Bloch y Braudel- que en los albores del siglo XX le imprimen una nueva direccionalidad al trabajo historiográfico. Direccionalidad que ya iniciada la segunda mitad el siglo XX será redefinida a partir de la obra y el influjo de las teorías estructuralistas -Levi Strauss, Lacan, Althusser-, posestructuralistas -Foucault, Derrida- y hermenéuticas -Gadamer, Koselleck-, así como por la filosofía de la diferencia -Deleuze- en el intersticio con la pragmática del lenguaje anglosajona -Wittgenstein, Searle, Austin, Rorty- y las nuevas filosofías de la historia -Hayden, LaCapra, Ricoeur-.

Todo este sustrato intelectual servirá para que las diferentes ciencias sociales y humanas realicen nuevas elaboraciones teóricas y epistemológicas y sirvan para potenciar el llamado "giro lingüístico" del que viene a ser tributario el resurgimiento de la narratividad en la historiografía de finales del siglo XX. El "giro lingüístico" propiamente dicho supone grandes aportes y mutaciones desde la filosofía y la lingüística para el campo de la historia, las filosofías subyacentes al mismo ofrecen una nueva lectura de la realidad, la cultura y la sociedad que posibilitan un retorno a narrativa histórica que ya Stone había adelantado en la década de los años setenta del siglo pasado.

Este retorno a la narrativa histórica traerá aparejado consigo el abandono de los rígidos esquematismos metodológicos que habían impuesto el marxismo y el estructuralismo durante más de medio siglo y hará aflorar un esfuerzo de construcción historiográfico donde la cientificidad y el rigor de la narración histórica no solo no riñan con el carácter poético de la obra, sino también donde el contenido y la forma puedan coexistir sin tener que sacrificar el uno por el otro. Asimismo, trabajos como los de E. J. Hobsbawm, George Duby, Carlo Ginzburg, Natalie Zemon Davis, Robert Dartnon y Simon 
Schama, por mencionar algunos, reflejan la capacidad de la nueva forma de hacer historia de producir narraciones verosímiles y alejadas del esquema encriptado con que se escribían numerosas obras en el marco de la historia serial y cuantitativa, y muestran que la relación entre arte y ciencia no necesariamente son irreconciliables.

\section{Referencias}

Aurell, J. (2005). La escritura de la memoria. De los positivismos a los postmodernismos. Valencia, España: Publicaciones de la Universidad de Valencia.

. (2006). La escritura de la memoria. Valencia: Universitat de Valencia/Universidad de Granada.

Barros, C. (1994). "Historia de las mentalidades, historia social". Estudios Históricos, Anuario de la Maestría en Historia de la Universidad Autónoma Metropolitana, México, 2, pp. 31-69, URL: http://www.hdebate.com/cbarros/spanish/hm_historia_social.htm.

Best, S. y Kellner, D. (1991). Postmodern Theory. Critical Interrogations. Hampshire and London: McMillian.

Bloch, M. (1982). Introducción a la historia. Buenos Aires, Argentina: Fondo de Cultura Económica.

Burke, P. (2003). Formas de hacer la historia. Madrid, España: Alianza Editorial. . (2006a). La revolución historiográfica francesa: La Escuela de los Annales 19291989. Barcelona, España: Editorial Gedisa, Segunda Reimpresión.

. (2006b). ¿Qué es la historia cultural? Barcelona, España: Editorial Paidós.

Collingwood, R. (1965). La idea de la historia. México. Fondo de Cultura Económica.

Davis, N. (1982). Le Retour de Martin Guerre. Paris, Francia: R. Laffont.

Derrida, J. (1988). Márgenes de la filosofia. Madrid, España: Editorial Cátedra. . (1989). La escritura y la diferencia. Barcelona, España: Editorial Antrophos.

Dilthey, W. (1944). "El origen de la hermenéutica". En: Obras de Wilhelm Dilthey. Volumen 5. México: Fondo de Cultura Económica. 
Dosse, F. (2003). La historia: conceptos y escrituras. Buenos Aires, Argentina: Ediciones Nueva Visión.

Febvre, L. (1970). Combates por la historia. Barcelona, España: Ariel.

Foucault, M. (1996a). Las palabras y las cosas. México: Siglo XXI Editores. . (1996b). Arqueología del saber. México: Siglo XXI Editores.

Gadamer, G. H. (2006). Verdad y método. Salamanca, España: Ediciones Sígueme.

Gagliano, R. (2006). "Las otras vidas de Clío. El 'giro lingüístico' y la construcción de la teoría en la investigación histórica". En: Jiménez García, Marco (comp.). Los usos de la teoría en investigación. México: Plaza y Valdés Editores.

Garcia Pallares-Burke, M. L. (2005). La nueva historia. Nueve entrevistas. Valencia: Publicaciones de la Universitat de Valencia/Universidad de Granada.

Ginzburg, C. (1986). El queso y los gusanos: El cosmos según un molinero del siglo XVI. Barcelona, España: Muchnik Editores.

Granja, J. (1998). Formaciones Conceptuales en Educación. México: Universidad Iberoamericana.

Hegel. G. W. (1999). Lecciones sobre la filosofía de la historia. Madrid: Editorial Alianza.

Hunt, L. (1989). The New Cultural History. California: Berkeley Press.

Koselleck, R. (1993). Futuro y pasado. Para una semántica de los tiempos históricos. Barcelona, España: Paidós.

. (2001). Los estratos del tiempo: estudios sobre la historia. Barcelona, España: Paidós.

. (2004). historia/Historia. Madrid, España: Editorial Trotta.

Lyotard, J. F. (2000). La condición postmoderna. Informe sobre el saber. Madrid, España: Editorial Cátedra.

Moro Abadía, O. (2006). La perspectiva genealógica de la historia. Santander. España: Servicio de Publicaciones de la Universidad de Cantabria.

Rorty, R. (1967). The Linguistic turn. Recent Essays in Philosophical Method. Chicago: University of Chicago Press. 
Schama, S. (1999). Rembrandt's Eyes. London: The Penguin Press.

Stone, L. (noviembre, 1979). "The Revival of Narrative”. Past and Present, 85, pp. 3-24.

Veyne, P. (1984). Cómo se escribe la historia. Foucault revoluciona la historia. Madrid, España: Alianza Editorial.

Viú, A. (2007). Imaginar el pasado, decir el presente. La novela histórica chilena (19852003). Santiago, Chile: RIL Editores.

White, H. (1992). El contenido de la forma. Narrativa, discurso y representación histórica. Barcelona, España: Paidós.

. (2003). El texto histórico como artefacto literario. Barcelona, España: Editorial Paidós. 